\title{
Lei Geral da Micro e Pequena Empresa
}

Walter Tadabiro Shima* Armando Dalla Costa

"De onde menos se espera, daí é que não sai nada mesmo", escreveu o barão de Itararé, autor de máximas memoráveis na primeira metade do século XX. No entanto, a Lei Geral da Micro e Pequena Empresa aprovada pela Câmara dos Deputados no dia 5 de setembro de 2006, por 308 votos favoráveis, seis votos contrários e três abstenções, depois de três anos de tramitação e muita negociação entre os partidos e o governo, mostra que nem sempre a máxima citada está certa.

Talvez o maior 'pacote' de estímulo à iniciativa privada de todos os tempos no Brasil, a Lei Geral foi aprovada e com ela o ambiente de negócios no país ganha em qualidade, além de estimular o espírito empreendedor. "Aprovamos hoje uma das legislações mais modernas do mundo; ela poderá beneficiar 69 milhões de pessoas que estão na informalidade", afirmou o relator do projeto da lei. O mesmo projeto, também conhecido como Supersimples foi aprovado no Senado Federal no dia 8 de novembro de 2006. No dia 14 de dezembro de 2006 o presidente da República Luiz Inácio Lula da Silva sancionou a Lei Geral da Micro e Pequena Empresa.

Segundo a Receita Federal, a Lei Geral trará uma renúncia fiscal de R \$ 5,4 bilhões por ano. No entanto esta renúncia pode não ser um problema para o governo. Segundo estudo realizado pela Fundação Getúlio Vargas (FGV), a redução tributária vai facilitar o crescimento das empresas de pequeno porte e isso, em pouco tempo, vai mais que compensar a perda imediata de arrecadação. Calcula-se também que a Lei Geral permitirá a formalização de aproximadamente um milhão de negócios informais dos 10,3 milhões existentes no país já em 2007, segundo dados do IBGE.

\footnotetext{
* Professor Adjunto II do Departamento de Economia da UFPR. E-mail: waltershima@ufpr.br

** Professor Adjunto I do Departamento de Economia da UFPR. E-mail: ajdcosta@,ufpr.br
} 


\section{Histórico da Lei Geral da Micro e Pequena Empresa}

O Brasil, um dos campeões em empreendedorismo do mundo, sofre com a burocracia. O candidato a empresário, para abrir o seu negócio no país, precisa recorrer, no mínimo, a dez órgãos diferentes. Além disso, são solicitados cerca de 80 documentos num processo caro e que pode levar até 152 dias, segundo estatística do Banco Mundial. O encerramento da empresa é ainda mais oneroso e complicado, podendo chegar a 10 anos.

A promulgação da reforma tributária em 2003, com alteração do artigo 146 da Constituição para criar uma lei complementar, que permitiu um tratamento diferenciado às micro e pequenas empresas, abriu caminho para que o segmento pudesse ter uma legislação própria. Afinal, os pequenos negócios são responsáveis por 20\% do Produto Interno Bruto, por $60 \%$ dos empregos gerados em todo país e por $99 \%$ das empresas formalmente estabelecidas. Este segmento precisava ter garantido ao mesmo tempo, a competitividade, o crescimento e a inserção tecnológica, o acesso às compras governamentais, à exportação, entre outros.

Em outubro de 2003, durante a Semana da Micro e Pequena Empresa, um trabalho coordenado pelo Serviço Brasileiro de Apoio às Micro e Pequenas Empresas (Sebrae), com ampla aprovação da sociedade, das entidades representativas da indústria (CNI), comércio (CNC), agricultura (CNA), transporte (CNT), e instituições financeiras, permitiu o surgimento de centenas de sugestões práticas para a melhoria do ambiente de todos os segmentos empresariais.

Mais de seis mil pessoas, entre empresários, lideranças e parlamentares, participaram dos encontros e forneceram subsídios para elaborar um projeto que tornasse o dia-a-dia das Micro e Pequenas Empresas (MPEs) mais simples, bem como estimulasse seu crescimento. A formulação da proposta foi sustentada ainda em pesquisas realizadas pelo Sebrae e outras instituições de renome, como o Banco Mundial e a consultoria McKinsey.

Aprovado por unanimidade na Comissão Especial da Microempresa no dia 13 de dezembro de 2005, o PLP 123/04 institui o Simples Nacional, apelidado de Supersimples, que substituirá integralmente o Simples Federal, em vigor no país desde 1996 (Lei 9.317) e cuja aplicação não é obrigatória para estados e municípios. O Simples em vigor abrange apenas a simplificação do pagamento de tributos federais para micro e pequenas empresas dos setores de indústria e comércio. 


\section{Destaques da Lei Geral da Micro e Pequena Empresa}

O Supersimples valerá para todo o país e deverá unificar nove impostos e contribuições - seis federais (IRPJ, IPI, CSLL, PIS/Pasep, Cofins e INSS Patronal), um estadual (ICMS) e um municipal (ISS) - e ainda uma contribuição para as entidades privadas de serviço social e de formação profissional vinculadas ao sistema sindical.

O projeto de lei prevê a presunção automática da opção pelo Supersimples. $\mathrm{Na}$ prática, isso significa que, no momento em que é constituída, a empresa entra automaticamente no sistema simplificado de tributação. Caso o empresário não queira aderir ao sistema Supersimples, ele terá que manifestar a intenção por ofício ao Cadastro Nacional.

De acordo com a proposta, no caso de licitações, as empresas que integrarem o Supersimples poderão participar exclusivamente de licitações públicas com valores até $R$ \$ 80 mil. Além disso, a administração pública deverá exigir das grandes empresas que participam de licitação a subcontratação de micro e pequenas empresas até 30\% do total licitado. O projeto também prevê que as instituições financeiras concedam linhas de crédito específicas para as MPEs.

\section{As principais inovações do projeto de lei consistem em:}

- Criar um sistema único de tributação e unificar nove impostos e contribuições;

- Definir como microempresa aquela com receita bruta anual de até $\mathrm{R} \$ 240$ mil e como empresa de pequeno porte aquela com receita bruta anual de até $\mathrm{R} \$ 2,4$ milhões;

- $\quad$ Estabelecer a presunção automática de opção pelo Simples Nacional a partir do momento da inscrição no Cadastro Nacional da Microempresa;

- Manter a obrigatoriedade de entrega da Relação Anual de Informações Sociais (Rais), para garantir as estatísticas do mercado de trabalho a cargo do Ministério do Trabalho e Emprego;

- Dispensar as empresas optantes pelo Simples Nacional do pagamento do salário-educação;

- Instituir o Comitê de Tributação, a ser definido em ato do Poder Executivo, composto por representantes da administração tributária do Executivo da União, dos estados e dos municípios; 
- Criar o fórum permanente das microempresas e empresas de pequeno porte, com participação de órgãos federais e das entidades vinculadas ao setor, para formular e coordenar uma política nacional de desenvolvimento das MPEs.

Os princípios que norteiam a Lei Geral da Micro e Pequena Empresa pretendem contribuir na geração de emprego, na distribuição de renda, na redução da informalidade, no incentivo ao crescimento das empresas, na ampliação da competitividade e desenvolvimento da economia.

\section{Os objetivos da Lei Geral da Micro e Pequena Empresa são:}

- $\quad$ Estabelecer um tratamento diferenciado e simplificado no âmbito da União, Estados, Municípios e Distrito Federal;

- Estimular a formação, a constituição, o funcionamento e o desenvolvimento das microempresas de pequeno porte;

- Racionalizar e simplificar procedimentos tributários por meio de recolhimento unificado de impostos e contribuições da União, dos Estados, dos Municípios e do Distrito Federal por meio de um sistema único de arrecadação, de âmbito nacional, com repasse de receita automático e incondicionado aos entes federados;

- Criar o cadastro integrado e unificado de dados e informações visando à desburocratização e simplificação da abertura, funcionamento e baixa de empresas;

- $\quad$ Simplificar as relações de trabalho;

- $\quad$ Facilitar o acesso ao crédito, a novos mercados e à tecnologia;

- $\quad$ Estimular o associativismo e a utilização de mediação e arbitragem na solução de conflitos.

\section{As principais medidas da Lei Geral da Micro e Pequena Empresa consistem} em:

- Reduzir e simplificar o pagamento de tributos federais, estaduais e municipais;

- $\quad$ Abrir o sistema à maioria dos prestadores de serviço;

- Permitir a compra e venda de bens e serviços, para o mercado nacional ou internacional, por meio de consórcios de empresas;

- Simplificar a declaração de renda e os registros e controles de operações contábeis;

- $\quad$ Facilitar o processo de fechamento de empresas; 
- $\quad$ Eliminar as exigências trabalhistas como fixação do Quadro de Trabalho;

- Determinar aos órgãos públicos que ofereçam pela Internet informações, orientações e formulários para alteração de contrato social e fechamento de empresas;

- $\quad$ Facilitar a abertura de empresas eliminando exigências de certidões;

- Prever a portabilidade das informações cadastrais da empresa em caso de mudança de banco;

- $\quad$ Facilitar o acesso ao crédito e a serviços financeiros;

- Determinar que bancos públicos criem linhas de crédito para as micro e pequenas empresas;

- $\quad$ Refinanciar dívidas tributárias das empresas de pequeno porte;

- Determinar a oferta de, no mínimo, $20 \%$ dos recursos destinados à inovação por órgãos governamentais;

- Autorizar o Ministério da Fazenda a zerar as alíquotas do IPI, da Cofins e do PIS/Pasep;

- Dar preferência em algumas licitações para as micro e pequenas empresas.

\section{Tabela de alíquotas da Lei Geral}

O Projeto de Lei enviado à Câmara e ao Senado previa uma divisão das empresas em 20 categorias diferentes de renda para recolhimento de impostos. Uma das alterações mais importantes feitas pelo relator da Lei Geral da Micro e Pequena Empresa na Câmara foi o acréscimo de duas novas categorias, incluindo empresas que faturam até 60 e entre 60 a 90 mil reais, como se pode observar na tabela. 
Tabela 1. Partilha do simples nacional: proposta

Inicial e alteração sugerida pelo relator

\begin{tabular}{|c|c|c|c|c|c|c|c|c|}
\hline \multicolumn{9}{|c|}{ Receita anual e alíquotas do Projeto original (em \%) } \\
\hline Receita bruta em 12 meses & Aliquota & IRPJ & CSLL & Cofins & Pis/Pasep & INSS & ICMS & Aliquota \\
\hline Até $\mathrm{R} \$ 60$ mil & - & - & - & - & - & - & - & 4,00 \\
\hline $\mathrm{R} \$ 60$ mil a $\mathrm{R} \$ 90$ mil & - & - & - & - & - & - & - & 4,48 \\
\hline $\mathrm{R} \$ 90$ mil a $\mathrm{R} \$ 120$ mil & 4,00 & 0,00 & 0,26 & 0,79 & 0,00 & 1,80 & 1,34 & 4,64 \\
\hline $\mathrm{R} \$ 120$ mil a $\mathrm{R} \$ 240$ mil & 5,47 & 0,00 & 0,30 & 1,08 & 0,00 & 2,17 & 1,86 & 5,47 \\
\hline $\mathrm{R} \$ 240$ mil a $\mathrm{R} \$ 360 \mathrm{mil}$ & 6,84 & 0,31 & 0,31 & 0,95 & 0,23 & 2,71 & 2,33 & 6,84 \\
\hline $\mathrm{R} \$ 360$ mil a $\mathrm{R} \$ 480 \mathrm{mil}$ & 7,54 & 0,35 & 0,35 & 1,04 & 0,25 & 2,99 & 2,56 & 7,54 \\
\hline $\mathrm{R} \$ 480$ mil a $\mathrm{R} \$ 600 \mathrm{mil}$ & 7,60 & 0,35 & 0,35 & 1,05 & 0,25 & 3,02 & 2,58 & 7,60 \\
\hline $\mathrm{R} \$ 600$ mil a $\mathrm{R} \$ 720$ mil & 8,28 & 0,38 & 0,38 & 1,15 & 0,27 & 3,28 & 2,82 & 8,28 \\
\hline $\mathrm{R} \$ 720$ mil a $\mathrm{R} \$ 840$ mil & 8,36 & 0,39 & 0,39 & 1,16 & 0,28 & 3,30 & 2,84 & 8,36 \\
\hline $\mathrm{R} \$ 840$ mil a $\mathrm{R} \$ 960 \mathrm{mil}$ & 8,45 & 0,39 & 0,39 & 1,17 & 0,28 & 3,35 & 2,87 & 8,45 \\
\hline $\mathrm{R} \$ 960$ mil a $\mathrm{R} \$ 1,08$ milhão & 9,03 & 0,42 & 0,42 & 1,25 & 0,30 & 3,57 & 3,07 & 9,03 \\
\hline $\mathrm{R} \$ 1,08$ milhão a $\mathrm{R} \$ 1,20$ milhão & 9,12 & 0,43 & 0,43 & 1,26 & 0,30 & 3,60 & 3,10 & 9,12 \\
\hline $\mathrm{R} \$ 1,20$ milhão a $\mathrm{R} \$ 1,32$ milhão & 9,95 & 0,46 & 0,46 & 1,38 & 0,33 & 3,94 & 3,38 & 9,95 \\
\hline $\mathrm{R} \$ 1,32$ milhão a $\mathrm{R} \$ 1,44$ milhão & 10,04 & 0,46 & 0,46 & 1,39 & 0,33 & 3,99 & 3,41 & 10,04 \\
\hline $\mathrm{R} \$ 1,44$ milhão a $\mathrm{R} \$ 1,56$ milhão & 10,13 & 0,47 & 0,47 & 1,40 & 0,33 & 4,01 & 3,45 & 10,13 \\
\hline $\mathrm{R} \$ 1,56$ milhão a $\mathrm{R} \$ 1,68$ milhão & 10,23 & 0,47 & 0,47 & 1,42 & 0,34 & 4,05 & 3,48 & 10,23 \\
\hline $\mathrm{R} \$ 1,68$ milhão a $\mathrm{R} \$ 1,80$ milhão & 10,32 & 0,48 & 0,48 & 1,43 & 0,34 & 4,08 & 3,51 & 10,32 \\
\hline $\mathrm{R} \$ 1,80$ milhão a $\mathrm{R} \$ 1,92$ milhão & 11,23 & 0,52 & 0,52 & 1,56 & 0,37 & 4,44 & 3,82 & 11,23 \\
\hline $\mathrm{R} \$ 1,92$ milhão a $\mathrm{R} \$ 2,04$ milhões & 11,32 & 0,52 & 0,52 & 1,57 & 0,37 & 4,49 & 3,85 & 11,32 \\
\hline $\mathrm{R} \$ 2,04$ milhões a $\mathrm{R} \$ 2,16$ milhões & 11,42 & 0,53 & 0,53 & 1,58 & 0,38 & 4,52 & 3,88 & 11,42 \\
\hline $\mathrm{R} \$ 2,16$ milhões a $\mathrm{R} \$ 2,28$ milhões & 11,51 & 0,53 & 0,53 & 1,60 & 0,38 & 4,56 & 3,91 & 11,51 \\
\hline $\mathrm{R} \$ 2,28$ milhões a $\mathrm{R} \$ 2,40$ milhões & 11,61 & 0,54 & 0,54 & 1,60 & 0,38 & 4,60 & 3,95 & 11,61 \\
\hline
\end{tabular}

Fonte: Elaborado pelos dos autores, a partir da proposta inicial e das alterações do Relator do Projeto na Câmara dos Deputados.

\section{Empresas que não podem optar pelo Supersimples}

De acordo com o substitutivo que institui o Supersimples, as micro e pequenas empresas que representam pessoas jurídicas estrangeiras, que tenham filiais em outros países ou mesmo que possuam estabelecimentos em mais de um estado não poderão aderir ao novo sistema de tributação.

Também ficarão de fora do sistema de tributação Supersimples as empresas constituídas sob a forma de sociedade por ações de capital aberto e as que exerçam atividade de banco comercial, de investimento e de desenvolvimento e de crédito.

O projeto também limita a participação no Supersimples das empresas que prestam serviço de comunicação (exceto as de mídia externa, as jornalísticas, de radiodifusão sonora e de sons e imagens); que realizam serviços de transporte intermunicipal ou interestadual; que sejam geradoras, transmissoras ou distribuidoras de energia; que fabriquem, importem, aluguem ou comercializem carros, motos e combustíveis (exceto postos de gasolina); que 
vendam bebidas alcoólicas, cigarros e armas; que prestem serviços de vigilância, limpeza ou conservação.

\section{Referências Bibliográficas}

AGÊNCIA CÂMARA. Saiba quais empresas não poderão optar pelo Simples. Disponível na Internet: [http://www.camara.gov.br/internet/agencia/imprimir.asp?pk=81729]. Acesso em: 07 dez. 2006.

- Câmara aprova Lei Geral da Micro e Pequena Empresa. Disponível na Internet: [http://www.camara.gov.br/internet/agencia/imprimir.asp?pk=92756]. Acesso em: 07 dez. 2006.

FUCS, José. Demorou! Depois de três anos de espera, o Congresso aprova uma lei que estimula o empreendedorismo e inibe a informalidade. Revista Época. 27/11/2006.

CNI. Cartilha da Lei Geral das Micro e Pequenas Empresas. Disponível na Internet: http://www.cni.org.br/empauta/pdf frente empresarial/cartilha.pdf] Acesso em: 07 dez. 2006.

SEBRAE-SP. Lei Geral. Um negócio do Brasil. Disponível na Internet: http://sebraesp.com.br/topo/politicas\%20publicas/arquivos politicas publicas/relatorio le i geral.pdf]. Acesso em: 07 dez. 2006.

SEBRAE-DF. Senado Federal aprova Lei Geral das Micro e Pequenas Empresas. Disponível na Internet:

[http://www.df.sebrae.com.br/mostraPaginaCorpo.asp?codPagina $=887 \&$ codServico $=44]$

Acesso em: 07 dez. 2006. 
